\title{
Environment-Related Malignant Neoplasm
}

National Cancer Institute

\section{Source}

National Cancer Institute. Environment-Related Malignant Neoplasm. NCI Thesaurus.

Code C4992.

Cancers caused by exposure to carcinogens in the general environment 